\title{
UN DOCUMENTO Y UN PROYECTO DE FRANCISCO EDUARDO TRESGUERRAS
}

\section{XAVIer Moyssén}

Un personaje muy controvertido en la arquitectura neoclásica de México, es Francisco Eduardo Tresguerras, autor de un número singular de edificios entre los que sobresale su obra máxima, la iglesia de la Orden del Carmen de Celaya. Tresguerras fue un artista versátil, después de dedicarse a la pintura, el grabado y la escultura, fue a dar de "hocicos en lo de arquitectura", según propia declaración; ${ }^{1}$ para ello no necesitó realizar estudios profesionales en la Academia de San Carlos de la Nueva España; fue un autodidacta formado como tantos constructores del siglo XIX, con el estudio y consulta de los libros de los tratadistas, en el caso suyo Jacopo Barozio Vignola estuvo a la cabeza. Con una ironía burlona de sí mismo, se decía "arquitete", mas en realidad lo que buscaba era burlarse mediante esa palabra, de otros arquitectos del Bajío, sus enemigos. Él sabía que la Academia habilitaba para construir, a quien lo merecía, mediante el grado de Académico de Mérito; con ese nombramiento se podía ejercer con libertad la profesión de arquitecto. En cuantas ocasiones fue necesario, proclamó que la Academia le reconocía "por su discípulo y me ha licenciado para cualesquiera obras y yo las he ejecutado hasta ahora con felicidad ..."2 Sin embargo, los documentos que acrediten el hecho posiblemente se extraviaron de los archivos de la Institución, pues no los registró Justino Fernández en su Guía de archivo de la antigua Academia de San Carlos 1781-1800. ${ }^{3}$ Es posible que una copia de esos papeles la haya manejado Abelardo Carrillo y Gariel, como se verá más adelante.

En 1794 Tresguerras viajó exprofeso a la capital del virreinato, para presentarse ante las autoridades de la Academia de San Carlos, a fin de que se le otorgara el nombramiento de Académico de Mérito en arquitectura; aceptando someterse a una serie de pruebas, de las cuales, al parecer, salió con éxito. Por desgracia, como se ha anotado, la documentación respectiva se ha extraviado, no se ha contado con mayor testimonio sobre el asunto, salvo lo que él mismo anotó en sus escritos. Hoy, gracias a un interesante documento manuscrito del propio Tresguerras, podemos con-

${ }^{1}$ En su Carta autobiogrática, reproducida como apéndice por Francisco de la Maza, en su edición de los Ocios Literarios, de Francisco Eduardo Tresguer ras, p. 200. México, UNAM, 1962

2 Idem, p 201

3 México, UNAM, 1968 
firmar su presencia ante la Academia y que cumplió con los requisitos a que le sometieron. ${ }^{4}$

Antes de pasar a comentar el documento, deseo anotar que en 1794 también hizo su solicitud de Académico de Mérito en el ramo de grabado, José Luis Rodríguez Alconedo, para lo cual presentó su conocido relieve cincelado en plata, con la efigie de Carlos IV. ${ }^{5}$ Dos años más tarde, el gran escultor Manuel Tolsá hizo lo mismo en el ramo de arquitectura. Las cosas en la burocracia virreinal debían caminar lentas, pues no fue sino hasta 1813 cuando le extendieron el codiciado nombramiento. ${ }^{6}$

El documento no está fechado, pero debe corresponder a un año posterior a 1795; se trata de una comunicación de Tresguerras a la Academia, para explicar su solicitud en favor del título, con el cual la Institución estaría representada en Celaya. Hace mención de haber cubierto todas las formalidades del caso, como el presentar el plano y el alzado de un edificio, to cual hizo en la Sala de Arquitectura, "de propia invención, sin plagio ni dolo", y lo certificó el arquitecto Antonio Velázquez (en realidad se trataba de Antonio González Velázquez) director del ramo correspondiente. Una vez terminada la prueba, todo quedó en poder de Antonio Piñeiro, Secretario de la Institución, así como otros "papeles, invenciones mías ya dibujadas y ya por escrito, de donde puede deducirse la teoría y práctica que tengo ..." Noticia importante es la que proporciona respecto a que no le fue posible esperar los resultados, pues le era indispensable el retornar a Celaya, lo cual pudo entorpecer los trámites hasta su conclusión.

Es de lamentar el extravío de la documentación de Francisco Eduardo Tresguerras en la Academia, pues a fin de cuentas nada se sabe oficialmente, sobre la resolución final, la cual pudo demorarse bastante como fue el caso de Manuel Tolsá. Una cita del documento la hizo Abelardo Carrillo y Gariel, lo que permite suponer que lo tuvo en sus manos, junto con otros papeles hoy perdidos. ${ }^{7}$ De todas formas el manuscrito que hoy se da a conocer, permite afirmar con seguridad la relación que existió entre el ilustre arquitecto celayense y la Academia de San Carlos.

En 1802 los carmelitas de Celaya le encargaron a Tresguerras, la construcción de su nueva iglesia; fray Antonio de San Valentín, Provincial de

\footnotetext{
${ }^{4}$ Debo una copia del manuscrito original, al arquitecto Pedto Ramírez Vázquez, a quien expreso desde aquí mi agradecimiento.

5) Justino Fernández, Guia del Archivo ..., p 96

's Eduardo Báez Macías, Guía del Archivo... 1801-1843, p. 43

${ }^{7}$ Las noticias las proporciona en su libro Datos sobre la Academia de San Carlos de Nueva España. El arte en México de 1781 a 1863. pp 30-31. México, 1939.
} 
la Orden, fue factor decisivo para contratarlo. Cuando falleció el fraile comisionaron al arquitecto para que presentara un proyecto para un monumento conmemorativo del religioso, que es el que aquí se publica; ignoro si llegó o no a construirlo. ${ }^{8}$

El diseño del monumento reúne las características que son comunes en su labor arquitectónica; si la obra debía construirse en el interior de la iglesia del Carmen, en nada desentonaría con la armonía decorativa del conjunto neoclasicista. Como fray Antonio de San Valentín había sido designado obispo de Santa Cruz de la Sierra, en las lejanas tierras de América del Sur, Tresguerras tuvo buen cuidado de coronar el monumento que proponía, con los símbolos de la mitra, el báculo y la cruz.

\section{DOCUMENTO}

Don Francisco Tresguerras presentó obras y solicita ser Académico de Mérito.

Don Francisco Tresguerras, profesor de las bellas artes, y residente en la ciudad de Celaya, con el debido respeto, digo:

Que habiéndome presentado por escrito, en esta ilustre Academia, y admitida mi petición, que reproduzco, la cual fue que según mi mérito e inteligencia, en el ramo de arquitectura, se me asociase en ella, como dispusiese vuestra excelencia y hallase por conveniente, para ejercer con arreglo y libertad dicho arte, en algunas obrillas que puedan proporcionárseme, y para que dicha ilustre Academia, tenga en aquella ciudad quien realice cualquiera de sus proyectos o comisiones.

En esta atención y en la de haber verificado todas las formalidades, que el caso requiere, como lo prueba el plan y alzado pedido a discreción y ejecutado por mí en la Sala de Arquitectura (cuya operación está autenticada por la certificación del señor director, don Antonio Velázquez, adjunta a dicho plan) de propia invención, sin plagio ni dolo, todo lo cual para en poder del señor secretario don Antonio Piñeiro, aún antes de la junta de enero de 95, pido; el que vuestra excelencia se digne atender a mi súplica, cuanto pueda indulgente, considerando que mi regreso me fue indispensable, y que me es muy gravoso repetir un viaje de casi sesenta leguas, con el abandono de mis intereses y familia, y más cuando quedan en poder de dicho señor director varios papeles, invenciones mías ya dibujadas y ya por escrito, de donde puede deducirse la teórica y práctica

${ }^{8}$ El proyecto fue publicado en el Anuario 1922-1923, de la Sociedad de Arquitectos Méxicanos. Fundada en 1919. México, 1929. 
que tengo sobre el particular, añadiendo por una sensible precisión, el que pues no soy conocido, me es inexcusable proferir, que de mi calidad y conducta podré satisfacer a la más severa escrupulosidad, y que por lo mismo, cualesquiera honra que se me confiera, recaerá en quien hará de ella el justo aprecio y la sabrá dar el valor que corresponda sin afectación ni altanería.

Así lo impetra de vuestra excelencia el que, sin embargo de lo dicho, se somete a sus sabias determinaciones.

Francisco Tresguerras [rúbrica] 


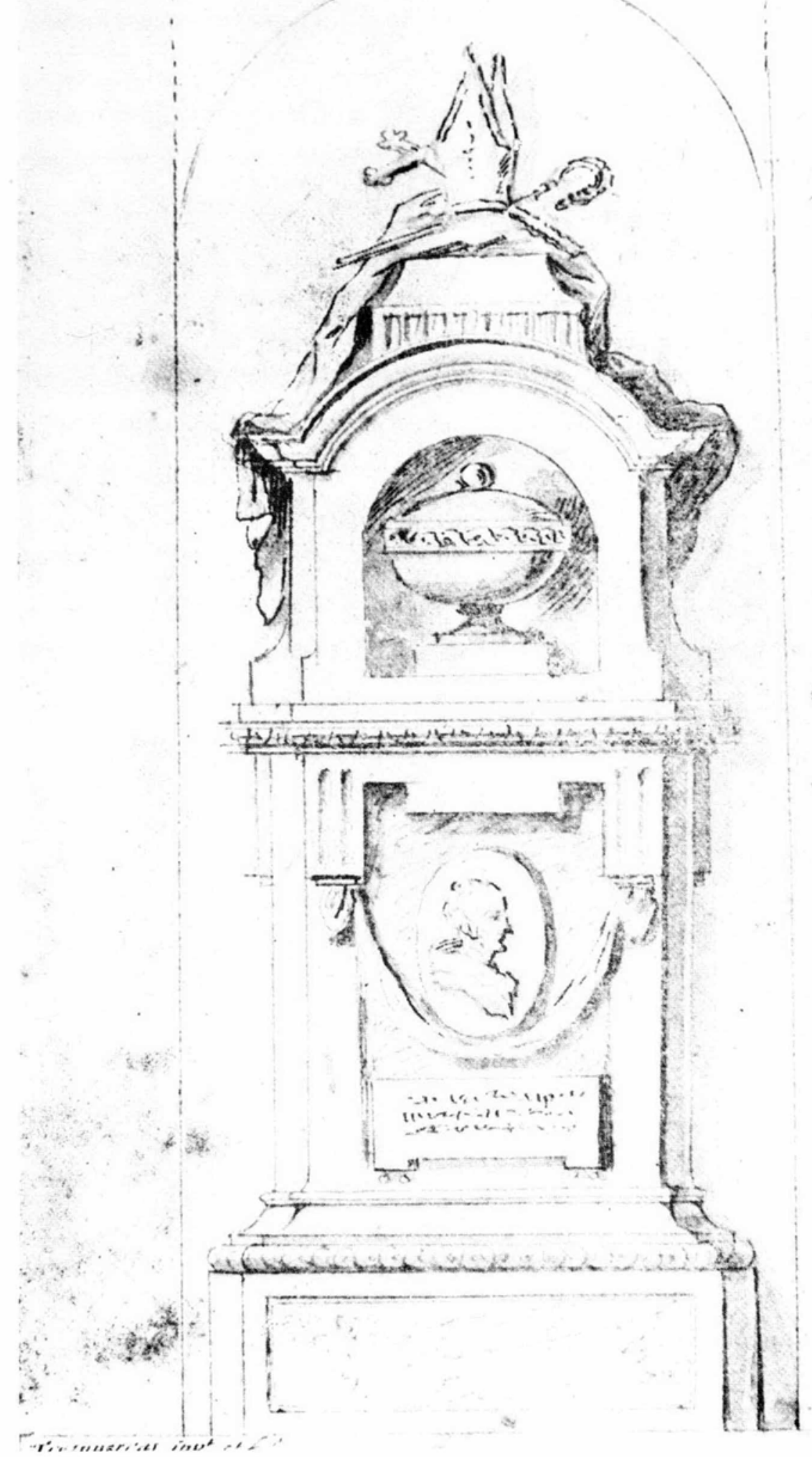

Francisco Eduardo Tresguerras. Proyecto para monumento funerario de Fray Antonio de San Fermín. 